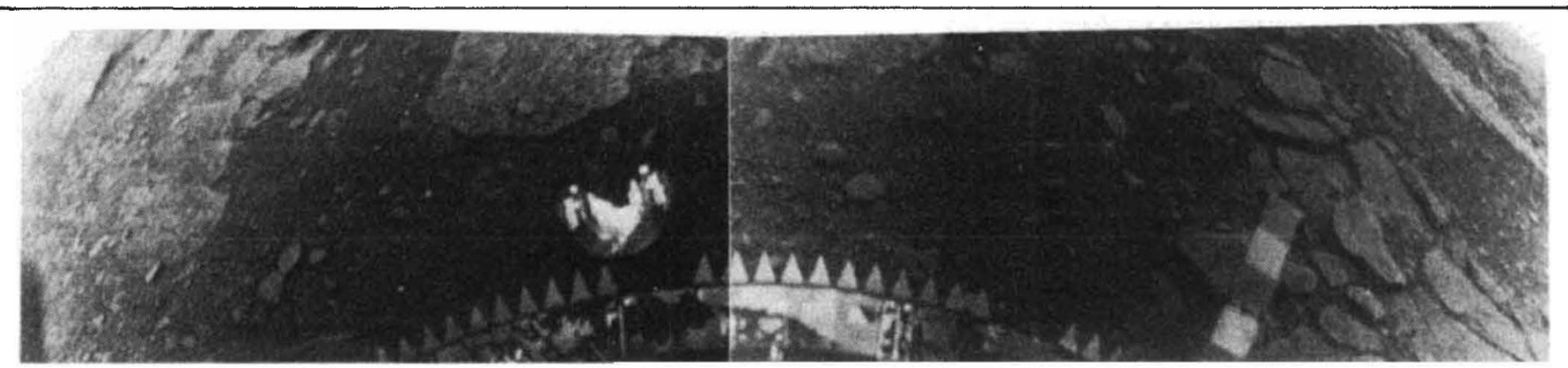

system for major element chemical analysis (Table 1).

Table 1 Oxide analyses of Venus surface rock in weight per cent

\begin{tabular}{lcc}
\hline Oxide & $\begin{array}{c}\text { Venera } \\
13 \text { site }\end{array}$ & $\begin{array}{c}\text { Venera } \\
14 \text { site }\end{array}$ \\
& 45 & 49 \\
$\mathrm{SiO}_{2}$ & 16 & 18 \\
$\mathrm{Al}_{2} \mathrm{O}_{3}$ & 10 & 8 \\
$\mathrm{MgO}$ & 9 & 9 \\
$\mathrm{FeO}$ & 7 & 10 \\
$\mathrm{CaO}$ & 4 & 0.2 \\
$\mathrm{~K}_{2} \mathrm{O}$ & 1.5 & 1.2 \\
$\mathrm{TiO}_{2}$ & 0.2 & 0.16 \\
$\mathrm{MnO}$ & & \\
\hline
\end{tabular}

At the Venera 13 site, on rolling uplands high on the flanks of Beta Regio, extensive coherent strata are seen, together with isolated rocks showing some evidence of erosion. The composition of the rock sample is close to that typical of terrestrial alkali basalts found in continental rift zones - a striking result when one recalls the proposed origin of Beta Regio as a rifted uplift over a hot-spot. Alkali basalts on Earth are associated with magma source regions rich in $\mathrm{CO}_{2}$ and the existence of such rocks on Venus lends support to the idea that $\mathrm{CO}_{2}$-driven explosive volcanism may occur there despite the high surface pressure.

The surface at the Venera 14 landing site, in a lowland area south-east of Beta Regio, is dominated by extensive horizontal strata, 10-100 $\mathrm{mm}$ thick, which have the appearance of lithified sediments in the process of being eroded. The composition, however, is again very close to that of a terrestrial primary volcanic product, in this case an ocean-floor tholeiitic basalt. It is tempting to reconcile the composition with the sedimentary character of the rock by assuming that it is some kind of pyroclastic material, but then the problem of finding sufficient volatiles to drive the eruption reappears. We should not jump to the conclusion that the tholeiitic nature of the Venera 14 rock necessarily implies that it was produced in a plate tectonic environment, as such a rock type would be on Earth. Indeed, too much must not be inferred about the interior of Venus from just two rock analyses; but it is ironic that each of the two analyses available, interpreted naively, supports one of the two main theories of Venus crustal structure.

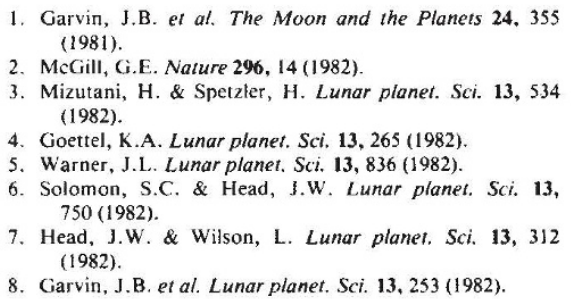

\title{
Punctuationism and Darwinism reconciled?
}

\section{The Lake Turkana mollusc sequence}

On 8 October, 1981 P G Williamson ${ }^{1}$ presented an extraordinarily "complete page in the history of evolution" in a very detailed sequence of fossil molluscs from the the eastern Turkana basin in East Africa. All of 13 lineages, including ten which could be followed for 4-5 million years, showed a pattern of evolution conforming to the 'punctuated equilbrium' model: change was concentrated in short (5,000-50,000 years) speciation events, between long periods (3-5 million years) of morphological stasis. How is such a pattern to be explained?

In the same issue, Jones ${ }^{2}$ pointed out that the rapidity with which change occurred is certainly no greater than can be brought about by conventional Darwinian selection. The real problem, as Williamson ${ }^{3}$ and others ${ }^{4}$ have made clear, is to explain the very long periods of stasis. Williamson favours the view, originally put forward by Eldredge and Gould", that stasis is primarily the result of "developmental constraint", which makes certain kinds of developmental change difficult or impossible, and that speciation must necessarily involve the dismantling of these mechanisms. He sees evidence of this process in the periods of extreme developmental instability (recorded as an increase in phenotypic variance) that accompany speciation events in his mollusc sequences.

A contrasting view is that stasis may be explained by stabilizing selection - that is selection favouring the typical members of a population rather than the extremes. If this explanation is correct, then as Maynard Smith points out in a new book (Evolution Now*) what we need is "a theory which says something about selection, and hence about the environment. Since the major component of the environment of most species consists of other species in the ecosystem, it follows that we need a theory of ecosystems in which the component species are evolving by natural selection."

Williamson's articles have stimulated a great deal of comment, a small part of which appears below. Questions are raised both as to the nature of the pattern recorded in the fossil lineages - whether or not the bursts of rapid change are truly genetic in origin - and its implications. The notion of developmental constraint is debated and more general points, such as whether the 'punctuated equilibrium' pattern could be brought about by varying rates of environmental change, or whether it could be an artefact of sampling time scales, are also examined.

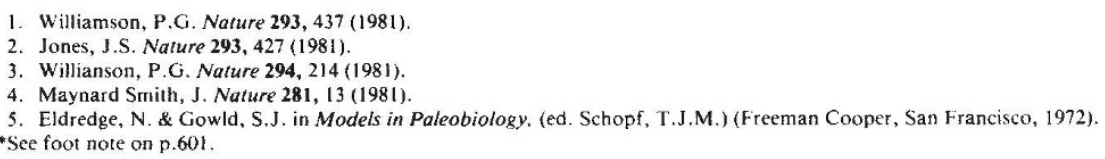

